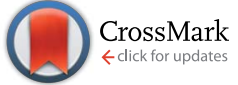

Cite this: RSC Adv., 2016, 6, 40090
Received 1st January 2016

Accepted 7th April 2016

DOI: $10.1039 / c 6 r a 00042 h$

www.rsc.org/advances

\section{Photosynthesized silver-polyaminocyclodextrin nanocomposites as promising antibacterial agents with improved activity}

\author{
Marco Russo, Alessandro Meli, Alberto Sutera, Giuseppe Gallo, Delia Chillura Martino, \\ Paolo Lo Meo* and Renato Noto
}

\begin{abstract}
Ag nanocomposites were prepared by photoreduction of ammoniacal silver acetate in the presence of poly-\{6-[3-(2-(3-aminopropylamino)ethylamino)propylamino]\}-(6-deoxy)- $\beta$-CD (amCD). The obtained systems were characterized by means of various complementary techniques (UV-Vis, FT-IR, TEM, SAED). In particular, FT-IR spectroscopy evidenced a partial oxidative degradation of the polyamine branches of the capping auxiliary, due to the fact that these groups function as a sacrificial reducing agent in the photoinduced formation of the Ag metal core. TEM and SAED micrographs showed that the Ag cores possess a relatively low polydispersity and a significantly crystalline character. The Ag-amCD systems were assayed for antibacterial activity, using Escherichia coli and Kocuria rhizophila as Gram-negative and Gram-positive tester strains respectively. In addition, the systems function as supramolecular drug carriers, able to bind the $\beta$-lactam antibiotic ampicillin, as demonstrated by polarimetric measurements. Antimicrobial assays revealed $\mathrm{MIC}_{90}$ values against $E$. coli and $K$. rhizophila as large as a 5 and $1 \mu \mathrm{g} \mathrm{mL}^{-1}$ respectively. Moreover, the interaction of the $A g-a m C D$ with ampicillin resulted in a synergistic improvement of the antibacterial activity. This study provides insights on the attractive possibility to use a photochemical methodology to produce bioactive supramolecular systems to be employed as powerful and tunable antimicrobial agents.
\end{abstract}

\section{Introduction}

Interest towards the antibacterial activity of silver and its compounds ${ }^{\mathbf{1}}$ has received a significant burst in recent years, due to the development of resistance to antibiotics by various pathogenic bacteria, and the consequent search for alternative biocides. In this context, the use of silver nanoparticles (Ag-NPs) benefits due to some interesting advantages. ${ }^{2} \mathrm{Ag}$ nanocomposites stabilized by various capping agents have shown the ability to penetrate the cell wall barrier, and then generate $\mathrm{Ag}^{+}$ ions under aerobic conditions. ${ }^{3}$ Released $\mathrm{Ag}^{+}$is known to interact in particular with the sulfhydryl groups of cysteinedependent enzymes ${ }^{\mathbf{4}, 5}$ and ROS-controlling systems. ${ }^{6}$ These processes, of course, are affected by the average size and surface area of the NPs, as well as by their morphology and by the nature of the capping agent used for their preparation. ${ }^{5}$ Stabilization of noble metal NPs in general is required in order to avoid their coalescence and, ultimately, their collapse into a bulk phase. For this purpose, amphiphilic donor species such as thiols, amines or carboxylic acids are generally used. ${ }^{7}$ Interesting alternatives are constituted by natural extracts, ${ }^{8}$ as well as

Università degli Studi di Palermo - Dipartimento di Scienze e Tecnologie Biologiche, Chimiche e Farmaceutiche, V.le delle Scienze, Parco d'Orleans, Pad. 17, 90128 Palermo, Italy.E-mail: paolo.lomeo@unipa.it by PAMAM and PPI-type dendrimers, ${ }^{9}$ which are able to provide an effective control over both size and polydispersity of the nanoparticles obtained. A sensible choice of the capping agent offers several profitable opportunities. Indeed, the capping agent might bind, either covalently or by means of supramolecular interactions, molecules possessing structural motifs recognizable by the cell wall, in such a way to improve the internalization of the nanocomposite itself. Alternatively, it might also function as a carrier for further drug/bioactive molecules able to act synergistically with the metal ion. Therefore, the construction of a capping agent designed on a supramolecular host system may constitute an intriguing task.

Under the latter viewpoint, the cyclodextrin (CD ${ }^{10}$ scaffold appears as an ideal candidate. Native CDs are cyclic oligosaccharides, which are perfectly biocompatible and can be easily subjected to chemical modification in several different ways. ${ }^{\mathbf{1 1}}$ Moreover, their supramolecular binding abilities have been thoroughly investigated. ${ }^{12}$ Consequently, CDs have been largely exploited for various applications, spanning from catalysts and artificial enzyme models ${ }^{\mathbf{1 3}}$ to drug carrier/delivery systems. ${ }^{\mathbf{1 4}}$ The use of native or modified CDs for the preparation of metal nanocomposites has been occasionally reported. ${ }^{15}$ We have recently shown that polyaminocyclodextrin derivatives may constitute a very interesting and promising class of capping agents for the preparation of silver nanocomposites. ${ }^{\mathbf{1 6}, 17} \mathrm{We}$ 
pursued the idea to obtain a species combining a dendrimerlike motif with the $\beta$-cyclodextrin $(\beta C D)$ scaffold. The synthesis of similarly structured derivatives had been already approached in various ways. ${ }^{18}$ However, we recently developed a simple and straight-forward protocol affording the desired products in high yields in two simple passages only, ${ }^{\mathbf{1 6}}$ namely the transformation of native $\beta C D$ into a heptakis-(6-halo)-(6deoxy) derivative, followed by a trivial nucleophilic displacement reaction with a suitable polyamine. In particular, we have employed the poly-(6-( $N, N$-dimethyl)propylene-diamino)-(6deoxy)- $\beta C D$ to stabilize $\mathrm{Ag}$ nanoparticles obtained by reduction of $\mathrm{AgNO}_{3}$ with formaldehyde. ${ }^{17}$ The composites obtained were characterized by means of UV-vis and Fourier-transform infrared (FT-IR) spectroscopy, Dynamic Light Scattering (DLS) and high-resolution Transmission Electron Microscopy (TEM) techniques, and then they were successfully tested as catalysts for the reduction of differently substituted nitroarenes with $\mathrm{NaBH}_{4}$. These nanocomposites have an onion-type structure, with a metal core $\left(c a .20-30 \mathrm{~nm}\right.$, depending on the $\mathrm{Ag}^{+} / \mathbf{a m C D}$ reaction ratio) surrounded by several layers of amCD units, held together both by mutual supramolecular interactions and by the complexation of unreduced $\mathrm{Ag}^{+}$ions. The layers are partly lost upon dilution, as it can be evidenced by the modifications of the characteristic surface plasmon resonance (SPR) band in the UVvis spectra. The presence of residual unreduced $\mathrm{Ag}^{+}$in the composite is due to the protecting action of the amCD itself, which is able, whenever present in strong excess, to inhibit the reduction reaction.

Thanks to their peculiar features, we reasoned that similarly structured composites may present improved biocompatibility and ability to trespass the bacterial cell wall, and that could constitute ideal systems to test the possible interaction with a suitable co-drug. In the present work we report on the photochemical synthesis and the characterization (UV-vis, FTIR, TEM) of Ag-NP nanocomposites stabilized by means of a different amCD derivative, namely the poly-\{6-[3-(2-(3-aminopropylamino)ethylamino)propylamino]\}-(6-deoxy)- $\beta C D$ (Fig. 1). These composites were assayed to assess their antibacterial activity towards the Gram-negative Escherichia coli and the Gram-positive Kocuria rhizophila strains used as bacterial testers. ${ }^{19-22}$ Finally, possible synergistic action with a typical $\beta$ lactam antibiotic such as ampicillin (amp, Fig. 2) was evaluated.

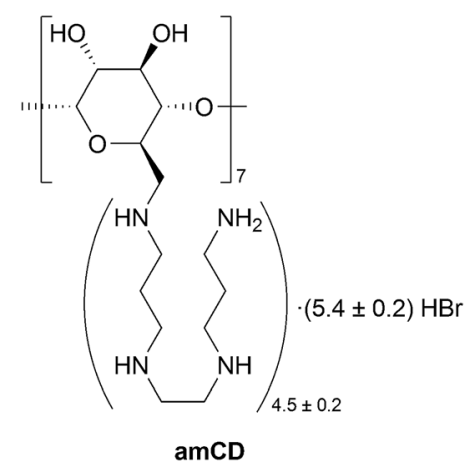

Fig. 1 Structure of amCD.

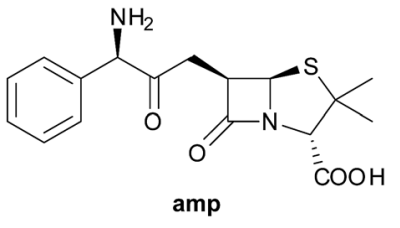

Fig. 2 Structure of amp.

\section{Results and discussion}

\section{Synthesis of the capping agent}

In agreement with literature, ${ }^{16}$ the chosen amCD derivative was directly obtained by reacting the heptakis-(6-bromo)-(6-deoxy)$\beta C D \quad(B r C D)^{23}$ with $N, N^{\prime}$-bis-(3-aminopropyl)-1,2-diamminoethane (Scheme 1) in a 20 -fold excess. It is worth noting that the polyamine functions as both the nucleophile and the solvent.

Owing to the occurrence of polysubstitution side-processes i.e. the possibility for a single polyamine unit to substitute two (or even more) bromine atoms on the BrCD - the product is actually constituted by a mixture of compounds, having a different number of polyamine branches; moreover, it is isolated as a partial hydrobromide. Nevertheless, the product was fully characterized by means of ESI-MS and potentiometric titration techniques. The latter one, in particular, allowed to determine the average number of polyamine branches $\left(n_{\mathrm{b}}=4.5 \pm 0.1\right)$ and hydrobromic acid units $\left(x_{\mathrm{HBr}}=5.4 \pm 0.2\right)$ per CD, the average molecular weight $(\langle\mathrm{MW}\rangle=2230 \pm 40)$ and equivalent weight $(\langle\mathrm{EW}\rangle=124 \pm 3)$, as well as to assess its behavior as a weak base. For the sake of clarity, the average equivalent weight is calculated as $\langle\mathrm{EW}\rangle=\langle\mathrm{MW}\rangle / 4 n_{\mathrm{b}}$, i.e. as the ratio between the average molecular weight and the average number of nitrogen atoms per $\mathrm{CD}$ unit (considered that each polyamine unit bears four $\mathrm{N}$ atoms). It is worth stressing here that, differently from previous literature reports, ${ }^{\mathbf{1 6 , 1 7}}$ we preferred the $\mathbf{B r C D}$ rather than the heptakis-(6-iodo)-(6-deoxy)- $\beta C D$ as the starting material for synthesizing the desired amCD, in order to avoid the presence of the iodide ion in the final product. However, the results of both potentiometric titration and NMR spectra showed that replacement of the leaving group on the starting electrophilic CD has no significant outcome on the reaction course and on the analytical characteristics of the final product.

\section{Synthesis of the nanocomposite}

For the synthesis of the desired Ag-NP nanocomposite, we reasoned that the presence of any component, apart from the

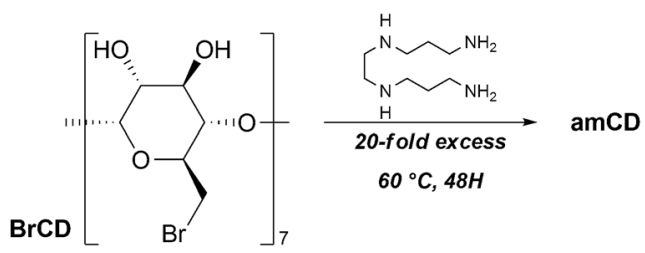

Scheme 1 Synthesis of amCD. 
$\mathrm{Ag}^{+}$ion, which could be somehow harmful to cell life, should have been excluded. Therefore, differently from our previous work, ${ }^{17}$ we chose to use the acetate (rather than the nitrate) as the starting silver salt to prepare stock solutions of the wellknown $\left[\mathrm{Ag}\left(\mathrm{NH}_{3}\right)_{2}\right]^{+}$complex. Then, we avoided the use of formaldehyde for the reduction reaction. We first attempted to use other biocompatible reducing agents such as glucose, sodium citrate or sodium ascorbate. In particular, test samples were prepared containing $\left[\mathrm{Ag}\left(\mathrm{NH}_{3}\right)_{2}\right]^{+}(1 \mathrm{mM})$ and $\mathbf{a m C D}(2 \mathrm{mN})$ in the presence of an excess of reductant $(5 \mathrm{mM})$, and kept at 40 ${ }^{\circ} \mathrm{C}$ for $90 \mathrm{~min}$ (which are the same conditions previously used for the reaction with $\mathrm{CH}_{2} \mathrm{O}$ ). In no case, however, we obtained satisfactory results. The reduction proceeded only up to a very poor extent in the presence of glucose, as accounted for by the low intensity observed for the expected SPR band $\left(\varepsilon<500, \lambda_{\max }\right.$ $405 \mathrm{~nm}$ ). No reaction occurred with sodium citrate; by contrast, ascorbate caused an immediate reaction with formation of dark brown, intractable precipitates. We therefore changed our strategy and, keeping into account the well-known sensitivity of silver salts to light, we tried to perform the preparation of the desired nanocomposites by means of a photochemical approach. The photoreduction of noble metals in general has been described in literature. ${ }^{24,25}$ It has been shown that the process involves the photoexcitation of a metal ion-ligand complex, resulting in an inner-sphere electron transfer process, from which the reduced metal is formed. The ligand, in turn, functions matter-of-factly as a sacrificial reducing agent, and ultimately undergoes oxidative degradation. In particular, tertiary amines are known to be converted into iminium ions (via the corresponding radical cations), ${ }^{25}$ which can be easily hydrolyzed. Photoinduced shape conversion of spherical AgNPs weakly capped by citrate ions has been reported. ${ }^{26}$

We could easily observe that a freshly prepared solution of $\left[\mathrm{Ag}\left(\mathrm{NH}_{3}\right)_{2}\right]^{+} 1 \mathrm{mM}$ with amCD $2 \mathrm{mN}$ rapidly turns reddish upon exposure to sunlight, revealing the undoubted formation of nanoparticles. Then, in order to standardize the operational conditions, we subjected the same system to irradiation by means of a simple commercial halogen lamp (at a $275 \mathrm{~W} \mathrm{~m}^{-2}$ irradiation power, see Experimental for details) for $10 \mathrm{~min}$. As expected, we obtained a stable reddish pseudo-solution, the UVvis spectrum of which revealed the characteristic SPR band centered at $\lambda_{\max }=406 \mathrm{~nm}(\varepsilon=3570$, Fig. 3). According to our previous work, ${ }^{17}$ the intensity of the SPR band for similarly structured systems can be assumed as a measure of the amount of reduced $\mathrm{Ag}$ present. Therefore, it is worth noting that the observed $\varepsilon$ value is lower than the one obtained for the reduction performed with formaldehyde $(\varepsilon=5540)$, all other conditions being equal. This finding implies that a signi-ficant amount of $\mathrm{Ag}^{+}$ion remains unreduced in the process. The AgNP system obtained is stable for weeks, if kept still in the dark. However, according to literature, ${ }^{27}$ we found out that it can be forced to precipitate by centrifugation, affording a brown material. We also observed that the precipitate obtained can be re-suspended in pure water by sonication, to afford again a quite stable pseudo-solution. The possibility to isolate and subsequently re-suspend an NP composite might be interesting, in view of possible applications. Therefore, we decided to

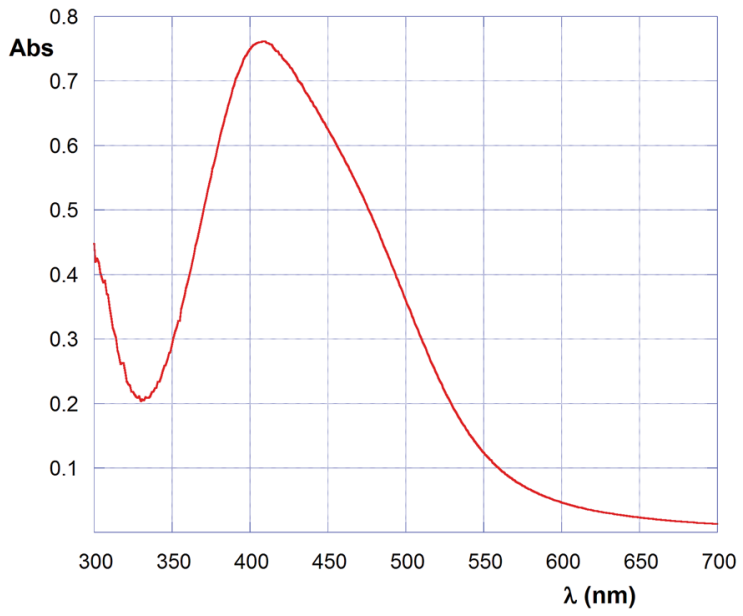

Fig. 3 UV-Vis spectrum of the "as-prepared" Ag-amCD pseudosolution.

subject to further characterization the "as-prepared" system, the forcedly precipitated solid and the sonicated re-suspended pseudo-solution as well. For the sake of clarity, hereinafter we will refer to the three systems as "AP Ag-amCD", "C Ag-amCD" and "PCR Ag-amCD" respectively.

\section{Characterization of the nanocomposites}

The FT-IR spectra of the free amCD and of the C Ag-amCD system precipitated by centrifugation are compared in Fig. 4. The main features present in the spectrum $(2 \% \mathrm{w} / \mathrm{w}$ in $\mathrm{KBr})$ of the capping agent are constituted by: (i) the $-\mathrm{OH}$ stretching band centered at $3250 \mathrm{~cm}^{-1}$; (ii) a signals cluster in the range $3000-2700 \mathrm{~cm}^{-1}$, relevant to the stretching of the $-\mathrm{CH}_{2}-$ groups of the polyamine units; (iii) a band at $1468 \mathrm{~cm}^{-1}$ relevant to the $-\mathrm{NH}$ - bending; (iv) a peculiar cluster of signals in the range $1190-960 \mathrm{~cm}^{-1}$, which constitutes the typical fingerprint of the CD scaffold. On passing to the composite, it must be preliminarily noticed that Ag-NPs in general show strong absorption of

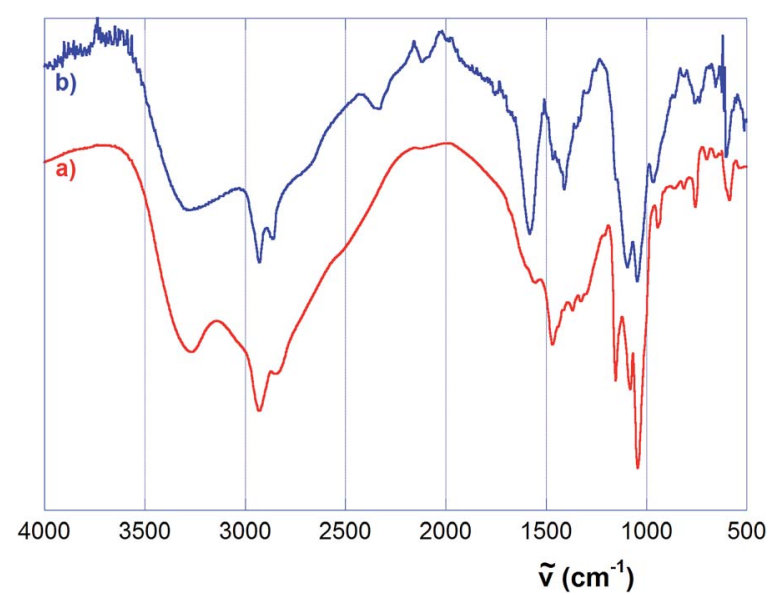

Fig. 4 FT-IR spectra of free $\operatorname{amCD}$ (a) and of the C Ag-amCD nanocomposite (b). 
IR radiation. Therefore, suitable baseline correction is needed in order to acquire the spectrum, ${ }^{17}$ which clearly presents all the signals expected for the presence of the amCD. This finding provides convincing evidence about the composite nature of the precipitate collected, and thus about the fact that the capping agent is stably bound to the NP metal core. However, we can also notice the enlargement of the $-\mathrm{OH}$ stretching band (which is shifted up to $3278 \mathrm{~cm}^{-1}$ ) and the significant presence of two new signals centered at 1581 and $1410 \mathrm{~cm}^{-1}$, in the typical position for the asymmetric and symmetric stretching of the carboxylate group respectively. The latter band overlaps with the aforementioned - NH- bending band (which is apparent as a shoulder). The presence of these signals indicates the occurrence of a significant oxidative degradation of the polyamine branches of the amCD. Although the mechanism of the photoinduced formation process for our Ag-NPs is currently under investigation, the latter finding supports the hypothesis ${ }^{25}$ that the capping agent actually functions as sacrificial reducing agent for the $\mathrm{Ag}^{+}$photochemical reduction.

Further characterization of the nanocomposites was achieved by means of high-resolution TEM techniques. In particular, we analyzed both the "AP Ag-amCD" and the "PCR AgamCD” pseudo-solutions. Representative micrographs are shown in Fig. 5 and 6 respectively. As we can easily see, the nanoparticles for the AP Ag-amCD system are nearly spherical in shape and quite well separated, with poor tendency to aggregation; moreover, the metal cores and present a good crystallinity, as evidenced by the relevant SAED (Selected Area Electron Diffraction) image, in particular by the bright spots superimposed to the diffraction rings due to the crystal orientation. Rings position is consistent with the $d$-spacing of the fcc phase of Ag indexed as 111, 200, 220 and 311 reflection from the center of the SAED pattern. Statistical analysis of the micrographs (the relevant distribution histogram is depicted in Fig. 7a) shows a slightly skewed size distribution, with a value a)

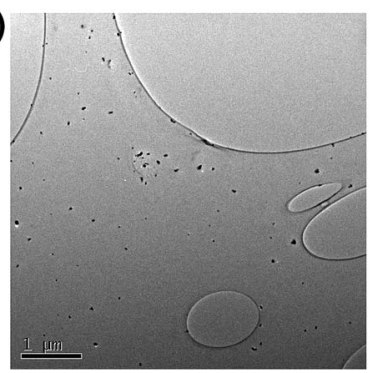

C)

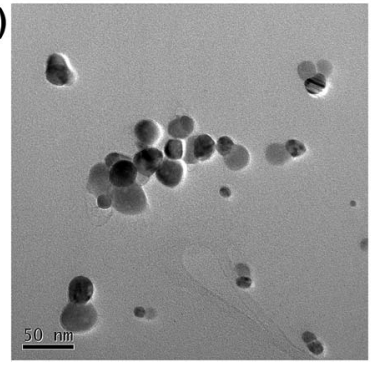

b)

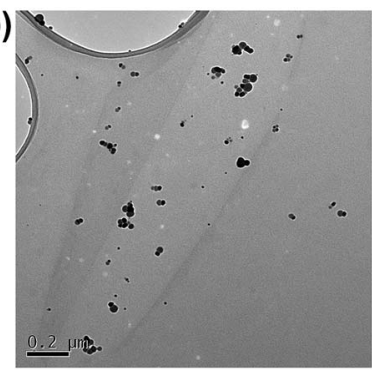

d)

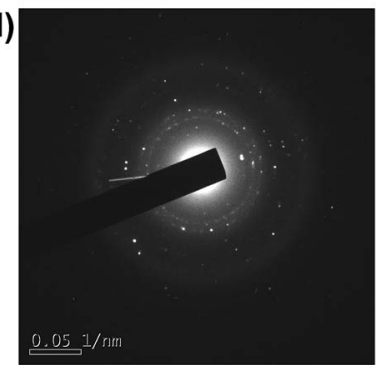

Fig. 5 TEM and SAED micrographs of the AP Ag-amCD nanocomposite.
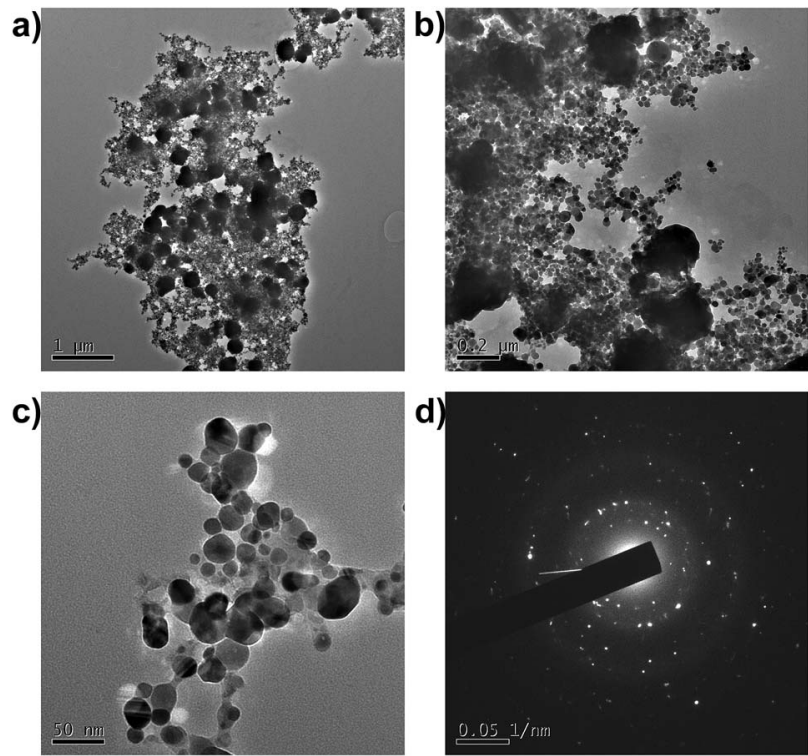

Fig. 6 TEM and SAED micrographs of the PCR Ag-amCD nanocomposite.

for the average diameter as large as $20 \mathrm{~nm}$ and a standard deviation of $7 \mathrm{~nm}$. On passing to the PCR Ag-amCD system, we can notice extensive aggregation, together with an increase in both average size and polydispersity of the metal cores (relevant distribution histogram in Fig. 7b). As a matter of fact, the average diameter increases up to $27 \mathrm{~nm}$ and the standard deviation up to $10 \mathrm{~nm}$. However, relatively few particles show significant modification in shape. On the grounds of a comparison between the SAED images for the two systems, redispersion seems to result in an increase of the degree of crystallinity, in agreement with the size increase inferred from TEM images.

The whole of these results suggests that the "as prepared" system should maintain a layer-structured coating shell, similar to the one described previously, ${ }^{17}$ despite the occurrence of partial oxidative degradation of the amCD. However, forced precipitation and subsequent re-suspension of the nanocomposite by sonication has heavy consequences. Loss of part of the coating is very likely to occur, resulting in aggregation and even coalescence in some cases. Moreover, further reduction of residual $\mathrm{Ag}^{+}$may take place, with consequent increase in size of the metal cores.
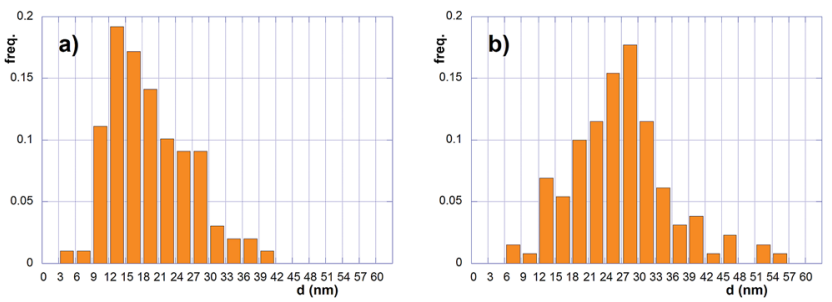

Fig. 7 Size distribution histograms of the Ag metal cores for (a) the AP $\mathrm{Ag}$-amCD and (b) the PCR Ag-amCD composites. 


\section{Antimicrobial activity}

Many reports describe the antimicrobial activity of biologically or chemically synthesized Ag-NPs showing Minimal Inhibitory Concentration (MIC) and Minimal Bactericidal Concentration (MBC) values ranging from 0.1 to $160 \mu \mathrm{g} \mathrm{mL}{ }^{-1}$ against either Gram-positive and Gram negative strains. ${ }^{20,28}$ In particular, Andrade $e t$ al. successfully tested the antimicrobial efficacy of $\beta$ cyclodextrin-coated pseudo-spherical Ag-NPs $(28 \mathrm{~nm}$ average diameter), revealing bactericidal effect at the concentration of $10 \mu \mathrm{g} \mathrm{mL}{ }^{-1}$ against the Gram-negative Escherichia coli used as tester strain. ${ }^{29}$ The dose-dependent antibacterial efficacy of AgNPs generally depends on different factors, including size and morphology, as well as the nature of the capping agent. ${ }^{\mathbf{1 , 5}}$ Therefore, in order to asses the antimicrobial activity of our $\mathrm{Ag}$ amCD nanocomposites, micro-biological assays were performed using the E. coli and the Gram-positive Kocuria rhizophila strains as testers. Preliminary agar diffusion tests were performed by spotting on bacterial overlays aliquots of suspensions containing different amounts (corresponding to 1 , $0.1,0.01$ and $0.001 \mu \mathrm{g}$ of total $\mathrm{Ag}$ respectively) of both the AP AgamCD and the PCR Ag-amCD systems; free amCD, ammoniacal silver acetate, the $\mathrm{Ag}^{+}$- $\mathbf{a m C D}$ complex prior to irradiation and the mother liquors from the forced precipitation of the composite were used as suitable controls. These preliminary tests revealed no or negligible inhibition of bacterial growth for the free amCD and for the mother liquors respectively, whereas the other tested silver sources showed significant antimicrobial activity against both the tester strains. In particular, for the tested composites 0.01 and $0.1 \mu \mathrm{g}$ of $\mathrm{Ag}$ were sufficient to afford growth inhibition of $K$. rhizophila and $E$. coli respectively. It is worth noting that the antibacterial efficacy measured as the area of bacterial growth inhibition halos, revealed that both AP and PCR Ag-amCD composites possess a similar activity, with the second one showing only a fair decrease in efficacy against both testers (Fig. 8). This finding parallels the observed morphological differences discussed previously. Indeed, owing to the larger average size and polydispersity of its NPs, a decreased activity for the PCR Ag-amCD could have been expected. Nevertheless, considered that differences in activity were in fact modest, the capability of being separated from aqueous phase

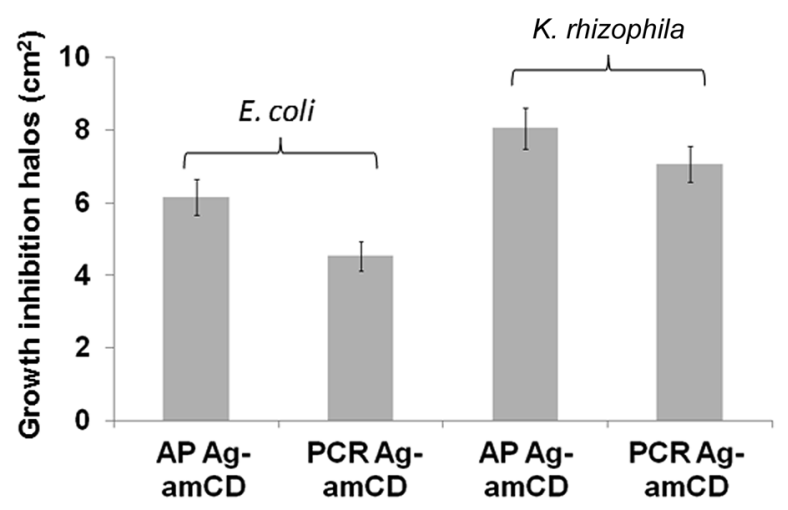

Fig. 8 Areas of bacterial growth inhibition halos produced by AP and PCR Ag-amCD. by centrifugation is undoubtedly a valuable characteristic for our nanocomposites. Therefore, everything considered, further investigations were carried out on the PCR Ag-amCD system only. As a final observation, lack of activity for the mother liquors indicates that unreduced $\mathrm{Ag}^{+}$ions possibly present in the AP Ag-amCD pseudo-solution co-precipitate within the $\mathrm{C}$ $\mathrm{Ag}$-amCD composite during centrifugation.

In order to achieve quantitative evaluation of the antibacterial efficacy of the PCR Ag-amCD composite, MIC and MBC tests were performed (relevant results are summarized in Table 1, see Experimental for details). In particular, we found values of $5 \mu \mathrm{g} \mathrm{mL}{ }^{-1}$ for both $\mathrm{MIC}_{90}$ and MBC against E. coli and 1 and 5 $\mu \mathrm{g} \mathrm{mL}^{-1}$ for $\mathrm{MIC}_{90}$ and $\mathrm{MBC}$ against $K$. rhizophila, respectively. We already mentioned that the mechanism of bactericidal actions of Ag-NPs has been extensively studied and different mechanisms of toxicity have been proposed. ${ }^{4-6,30}$ These include bacterial cell membrane disruption, inhibition of respiratory enzymes, inhibition of cell-wall biosynthesis and interaction with bacterial DNA. In all these events the capability of silvernanocomposite to produce Reactive Oxygen Species (ROS) and to release $\mathrm{Ag}^{+}$by the $\mathrm{Ag}$-NPs oxidation is fundamental to exert biological activity. ${ }^{1,3}$ The quantitative data of $\mathrm{MIC}_{90}$ and $\mathrm{MBC}$ values obtained for PCR Ag-amCD were very close or identical to the ones measured for the control silver acetate or the $\mathrm{Ag}^{+} \cdot$ amCD not irradiated pre-complex. This evidence suggests a considerable capability of $\mathrm{Ag}^{+}$production from the PCR AgamCD. It is worth stressing that MIC values for PCR Ag-amCD are similar or lower than those reported in other works against the same bacterial strains, ranging from 0.25 to $100 \mu \mathrm{g} \mathrm{mL}{ }^{-1}$, in dependence of the capping agent and the Ag-NP size. ${ }^{2}$ In particular, for Ag-NPs having a size similar to that of PCR AgamCD, MICs against $E$. coli ranging from 10 to $75 \mu \mathrm{g} \mathrm{mL}{ }^{-1}$ have been reported. ${ }^{2}$ As long as $K$. rhizophila strain is concerned, the lowest Ag-NP MIC ever reported is as large as $4 \mu \mathrm{g} \mathrm{mL}{ }^{-1} .^{21}$

The possible combination of antimicrobial activity of Ag-NPs and antibiotic molecules has been explored giving interesting results whenever the combined system showed improved efficacy. ${ }^{31-33}$ In particular, synergistic effect has been observed combining Ag-NPs and ampicillin (amp) against E. coli strains. ${ }^{32,33}$ In these cases the interaction between Ag-NP and carrier. The ability of amCD to bind amp was positively assessed by means of polarimetric measurements (see Experimental for the antibiotic may be postulated on the grounds of the antimicrobial efficacy enhancement found. Due to its peculiar structure, Ag-amCD functions as a potential supramolecular details), ${ }^{34}$ which allowed us to estimate for the amCD -amp complex a stability constant as large as $650 \pm 100 \mathrm{M}^{-1}$ (Fig. 9). Thus, amp was added to both the $\mathrm{Ag}^{+} \cdot \mathbf{a m C D}$ pre-complex and the PCR Ag-amCD composite in a $1: 1$ weight ratio, and the resulting complexes were subjected to tests. The antimicrobial assays performed on E. coli revealed a 5-fold improvement of bacterial-growth inhibitory and bactericidal activity for the PCR $\mathrm{Ag}$-amCD + amp system. This result is particularly interesting, because the amount of amp used is significantly smaller as compared with other works, ${ }^{35}$ and is at least one order of magnitude lower than the MIC and MBC values against E. coli strain calculated in this study (i.e. 10 and $25 \mu \mathrm{g} \mathrm{mL} \mathrm{m}^{-1}$, 
Table 1 MIC $_{90}$ and MBC values of Ag composites against $E$. coli and K. rhizophila strains ${ }^{a}$

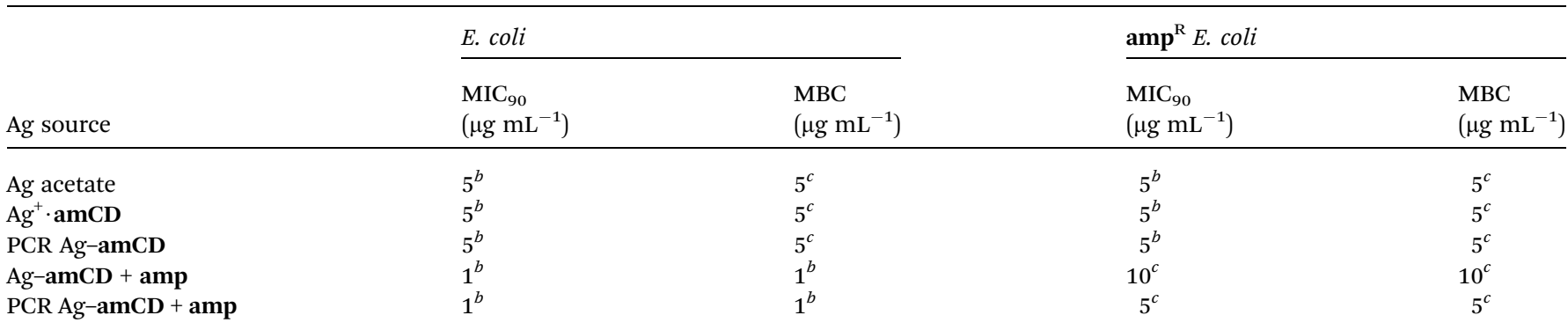

\begin{tabular}{|c|c|c|}
\hline & \multicolumn{2}{|c|}{ K. rhizophila } \\
\hline $\mathrm{Ag}$ acetate & $0.5^{b}$ & $0.5^{c}$ \\
\hline $\mathrm{Ag}^{+} \cdot \mathbf{a m C D}$ & $1^{b}$ & $1^{b}$ \\
\hline PCR Ag-amCD & $1^{b}$ & $5^{b}$ \\
\hline
\end{tabular}

${ }^{a}$ Statistical significance of MIC and MBC values was calculated by one way ANOVA test using values obtained from spectrophotometric measurements of bacterial growth and viable bacterial cell counts, respectively. ${ }^{b} p<0.01 .{ }^{c} p<0.05$.

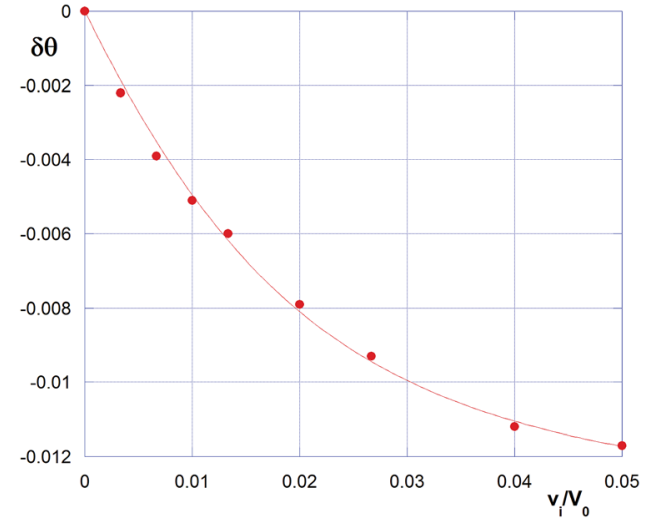

Fig. 9 Polarimetric determination of the amCD.amp binding constant.

respectively). In particular, the MIC value is in agreement with the one reported in literature for the same strain. ${ }^{19,36}$ Further control tests were performed with an E. coli strain which expresses a $\beta$-lactamase gene bla, contained in a high-copy number DNA vector plasmid and conferring high level of amp resistance (more than $100 \mu \mathrm{g} \mathrm{mL}^{-1}$ ). In particular, PCR AgamCD + amp $\mathrm{MIC}_{90}$ and MBC values against the $\mathbf{a m p}^{\mathrm{R}} E$. coli strain resulted comparable to the ones found for the PCR AgamCD alone. The latter result indicates that the improvement of antimicrobial activity is specifically due to synergistic action of the composite and amp. Noticeably, the PCR Ag-amCD + amp system showed increased activity as compared to PCR Ag-amCD even if sub-lethal amounts of amp were bound on the $\mathrm{Ag}$ nanocomposite, suggesting that the antimicrobial activity of this system still resides in the activity of Ag-NP whereas the amp molecule can increase the affinity of Ag-NPs surface for the bacterial cell wall, as already proposed by Fayaz et $a l^{33}$
Therefore, based on these considerations, the PCR Ag-amCD system exerts a powerful antibacterial efficacy and may have an applicability in those fields where antimicrobial capability is a desired feature.

\section{Experimental}

\section{Materials and instrumentation}

All commercial (Aldrich, Fluka) reactants and materials were used as purchased, with no further purification. The noncommercial BrCD was prepared according to literature. ${ }^{16}$

UV-vis spectra were recorded on a Beckman DU 800 spectrophotometer. FT-IR spectra $(2 \%$ in $\mathrm{KBr})$ were acquired on a Bruker VERTEX 70 apparatus. NMR spectra were recorded on a Bruker $300 \mathrm{mHz}$ AS series spectrometer. ESI-MS mass spectra were acquired in positive mode on an AGILENT Technologies 6540 UHD Accurate Mass Q-TOF LC-MS apparatus (1 kV nozzle voltage, $250 \mathrm{~V}$ fragmentor voltage). TEM micrographs were acquired using a JEM-2100 (JEOL, Japan) electron microscope operating at $200 \mathrm{kV}$ accelerating voltage. A drop of each suspension was put onto a $3 \mathrm{~mm} \mathrm{Cu}$ grid "lacey carbon" for analysis and let the solvent to complete evaporation. Polarimetric measurements were performed on a JASCO P-1010 polarimeter.

\section{Synthesis and characterization of amCD}

Poly-\{6-[3-(2-(3-aminopropylamino)ethylamino)propylamino]\}(6-deoxy)- $\beta C D$ (amCD) was synthesized, according to the procedure reported in previous works, ${ }^{16}$ by reacting the heptakis-(6-bromo)-(6-deoxy)- $\beta \mathrm{CD}^{23}$ (315 mg, $0.2 \mathrm{mmol}$ ) with $N, N^{\prime}$-bis(3-aminopropyl)-1,2-diammino-ethane (5 mL, $4.76 \mathrm{~g}, 0.0273$ $\mathrm{mol}$ ) at $60{ }^{\circ} \mathrm{C}$ for $48 \mathrm{~h}$. The reaction crude was diluted with 10 $\mathrm{mL}$ of methanol and the solution was dropped under vigorous stirring into $300 \mathrm{~mL}$ of cold diethyl ether. The system was 
allowed to settle for a few hours and then decanted, affording a brownish slurry. The slurry was dissolved in $10 \mathrm{~mL}$ of methanol and again dropped under stirring into $200 \mathrm{~mL}$ of diethyl ether, to afford a second amorphous solid. This dissolutionprecipitation procedure was repeated other two or three times, until a pale yellow solid was obtained. The product was finally filtered off and dried under vacuum overnight at $50{ }^{\circ} \mathrm{C}$. Yield $419 \mathrm{mg}$ (94\%).

The product decomposes on heating over $190{ }^{\circ} \mathrm{C}$; FT-IR: see text; ${ }^{1} \mathrm{H}$ and ${ }^{13} \mathrm{C}$ NMR spectra were coincident with the ones reported elsewhere ${ }^{16}$ for the product obtained starting from the heptakis-(6iodo)-(6-deoxy)- $\beta C D:{ }^{1} \mathrm{H}$ NMR (DMSO- $\left.d 6\right) \delta$ 1.59, 1.63 (two overlapped $\mathrm{m},-\mathrm{CH}_{2}-\mathrm{CH}_{2}-\mathrm{CH}_{2}-$ ), 2.43, 2.55 (two overlapped $\mathrm{m},-\mathrm{CH}_{2}-$ $\mathrm{N} \angle$ ) , 2.60, 2.63 (two overlapped br m, $-\mathrm{CH}_{2}-\mathrm{NH}-$ and $\mathrm{H}(6) \mathrm{CD}$ ), 2.82 (m, $-\mathrm{CH}_{2}-\mathrm{NH}_{2}$ and $\mathrm{H}(6) \mathrm{CD}$ ), 3.35 (br s, H(2)CD), 3.50 (br s, H(4)CD), 3.66 (br s, H(3)CD), 3.76 (br s, H(5)CD), 4.91 (br s, H(1)CD), 4.95 (br $\mathrm{s},-\mathrm{OH},-\mathrm{NH}-)$ ppm; ${ }^{13} \mathrm{C}$ NMR $\delta 27.39,28.32\left(-\mathrm{CH}_{2}-\mathrm{CH}_{2}-\mathrm{CH}_{2}-\right)$, $38.48\left(-\mathrm{CH}_{2}-\mathrm{NH}_{2}\right), 46.61,47.36,48.94\left(-\mathrm{CH}_{2}-\mathrm{N} \angle\right), 48.70-49.60$ (cluster, C(6)CD), 70.36 (C(5)CD), 72.32 (C(2)CD), 72.80 (C(3)CD), 82.20-85.70 (cluster, C(4)CD), 102.45 (C(1)CD) ppm; high-resolution ESI-MS (m/z): $1114.8004\left[\mathrm{C}_{98} \mathrm{H}_{210} \mathrm{~N}_{28} \mathrm{O}_{28} \cdot 2 \mathrm{H}\right]^{2+}$ (calcd 1114.8007); $1038.6996\left[\mathrm{C}_{90} \mathrm{H}_{188} \mathrm{~N}_{24} \mathrm{O}_{28} \cdot \mathrm{Na} \cdot \mathrm{H}\right]^{2+}$ (calcd 1038.6995); 1027.7085 $\left[\mathrm{C}_{90} \mathrm{H}_{188} \mathrm{~N}_{24} \mathrm{O}_{28} \cdot 2 \mathrm{H}\right]^{2+}$ (calcd 1027.7085); $951.6077\left[\mathrm{C}_{82} \mathrm{H}_{166} \mathrm{~N}_{20} \mathrm{O}_{28}\right.$ $\cdot \mathrm{Na} \cdot \mathrm{H}]^{2+}$ (calcd 951.6073); $940.6166\left[\mathrm{C}_{82} \mathrm{H}_{166} \mathrm{~N}_{20} \mathrm{O}_{28} \cdot 2 \mathrm{H}\right]^{2+}$ (calcd 940.6163); $853.5242 \quad\left[\mathrm{C}_{74} \mathrm{H}_{144} \mathrm{~N}_{16} \mathrm{O}_{28} \cdot 2 \mathrm{H}\right]^{2+}$ (calcd 853.5241); $743.5368 \quad\left[\mathrm{C}_{98} \mathrm{H}_{210} \mathrm{~N}_{28} \mathrm{O}_{28} \cdot 3 \mathrm{H}\right]^{3+} \quad$ (calcd 743.5363); 685.4752 $\left[\mathrm{C}_{90} \mathrm{H}_{188} \mathrm{~N}_{24} \mathrm{O}_{28} \cdot 3 \mathrm{H}\right]^{3+}$ (calcd 685.4748); $634.4719\left[\mathrm{C}_{82} \mathrm{H}_{166} \mathrm{~N}_{20} \mathrm{O}_{28}\right.$ $\cdot \mathrm{Na} \cdot 2 \mathrm{H}]^{3+}$ (calcd 634.4706); $627.4139\left[\mathrm{C}_{82} \mathrm{H}_{166} \mathrm{~N}_{20} \mathrm{O}_{28} \cdot 3 \mathrm{H}\right]^{3+}$ (calcd 627.4133); $569.3524 \quad\left[\mathrm{C}_{74} \mathrm{H}_{144} \mathrm{~N}_{16} \mathrm{O}_{28} \cdot 3 \mathrm{H}\right]^{3+}$ (calcd 569.3518); $557.9045 \quad\left[\mathrm{C}_{98} \mathrm{H}_{210} \mathrm{~N}_{28} \mathrm{O}_{28} \cdot 4 \mathrm{H}\right]^{4+} \quad$ (calcd 557.9040); 514.3585 $\left[\mathrm{C}_{90} \mathrm{H}_{188} \mathrm{~N}_{24} \mathrm{O}_{28} \cdot 4 \mathrm{H}\right]^{4+}$ (calcd 514.3579).

Potentiometric titrations were performed according to the procedure reported elsewhere. ${ }^{16}$ A weighed amount (ca. $50 \mathrm{mg}$ ) of amCD was dissolved with $10 \mathrm{~mL}$ of freshly double-distilled water in a jacketed vessel (thermostated at $25{ }^{\circ} \mathrm{C}$ ), then $5 \mathrm{~mL}$ of a standard $\mathrm{HCl} 0.1 \mathrm{M}$ were added, and the resulting solution was degassed bubbling into it a fine stream of Ar for $15 \mathrm{~min}$. The resulting solution, kept under magnetic stirring, was then titrated with a standard $\mathrm{NaOH} 1 \mathrm{M}$ solution introduced by means of a Chemetron micrometric syringe, recording the $\mathrm{pH}$ distilled water (ca. $50 \mathrm{~mL}$ ); then a slight excess of $\mathrm{NH}_{3} 1 \mathrm{M}$ was added dropwise until the solution turned perfectly clear, and the volume was finally adjusted to $100 \mathrm{~mL}$ with distilled water. The solution can be stored indefinitely in the dark. In parallel, a stock solution of amCD $6 \mathrm{mN}$ was prepared by dissolving $14.76 \mathrm{mg}$ of amCD (6.6 $\mu \mathrm{mol}, 0.12 \mathrm{meq}$.) in $20 \mathrm{~mL}$ of distilled water.

In order to prepare the $\mathrm{AP} \mathrm{Ag}$-amCD nanocomposite, $1.8 \mathrm{~mL}$ of water, $200 \mu \mathrm{L}$ of ammoniacal $\mathrm{Ag}$ acetate $15 \mathrm{mN}$ solution and $1.0 \mathrm{~mL}$ of amCD $6 \mathrm{mN}$ solution were rapidly mixed in a screwcap vial. The carefully closed vial containing the solution was accommodated in a box having the inner walls covered in tinfoil, and exposed for $10 \mathrm{~min}$ to the light of a common $50 \mathrm{~W}$ halogen lamp placed at a distance of $12 \mathrm{~cm}$. The resulting amber red solution was immediately stored in the dark.

The C Ag-amCD precipitated composite was obtained by subjecting a freshly prepared sample of AP Ag-amCD to centrifugation at $14000 \mathrm{rpm}$ for $30 \mathrm{~min}$. Then, the clear, almost colourless supernatant liquor was carefully decanted and the brown residue was lyophilized overnight. Yield $12.3 \mathrm{mg}$.

The PCR Ag-amCD system was prepared by subjecting $1 \mathrm{~mL}$ of freshly prepared AP Ag-amCD pseudo-solution to centrifugation at 14000 for $30 \mathrm{~min}$ in an Eppendorf vial. The mother liquors were carefully pipetted, and replaced with $1 \mathrm{~mL}$ of fresh water. The system was then subjected to sonication using a Sonics and Material Inc. Vibra cell sonicator for $10 \mathrm{~s}$.

\section{Polarimetric determination of the amCD-amp binding constant}

According to the standard procedure reported in literature, ${ }^{34}$ stock solutions of amCD (2.5 mM) and amp (150 mM) were prepared by dissolving the proper amounts of substance in pure water. Samples were prepared by adding different microamounts (from 0 up to $150 \mu \mathrm{L}$ ) of the guest amp solution to 3 $\mathrm{mL}$ of the host amCD solution. Then, the optical activities of the samples were measured. Due to the fact that the chiral guest amp possesses a non-null optical activity, regression analysis of polarimetric data was accomplished by means of the proper equation derived analytically (which is a generalization of the equation used in previous works ${ }^{34}$ ):

$$
\begin{aligned}
& \delta \vartheta_{i}=\left[\vartheta_{i}\left(1+v_{i} / V_{0}\right)-\vartheta_{0}-G_{0}^{0} \frac{v_{i}}{V_{0}} \Theta_{\mathrm{G}}\right]= \\
& =\frac{\Delta \Theta}{2}\left(H_{0}^{0}+G_{0}^{0} \frac{v_{i}}{V_{0}}+\frac{1+v_{i} / V_{0}}{K}-\sqrt{\left(H_{0}^{0}+G_{0}^{0} \frac{v_{i}}{V_{0}}+\frac{1+v_{i} / V_{0}}{K}\right)^{2}-4 H_{0}^{0} G_{0}^{0} \frac{v_{i}}{V_{0}}}\right)
\end{aligned}
$$

value resulting after each titrant addition $(2.5 \mu \mathrm{L})$ with a common pH-meter. Data were analyzed by means of the proper fitting equation derived analytically, providing that the product behaves as a mixture of four independent monoprotic virtual bases.

\section{Preparation of the Ag-amCD composites}

A stock solution of ammoniacal $\mathrm{Ag}$ acetate $15 \mathrm{mM}$ was prepared as follows: $250.3 \mathrm{mg}$ of salt $(0.15 \mathrm{mmol})$ were dissolved in where, for the generic $i$-th sample, $\theta_{i}$ and $\theta_{0}$ are the optical rotations measured for the sample and the pure host solution respectively, $v_{1}$ is the volume of amp added, $V_{0}$ is the volume of amCD solution, $\Theta_{\mathrm{G}}$ is the molar optical rotation of the guest, $H_{0}^{0}$ and $G_{0}^{0}$ are the analytical concentrations of the host and guest solutions respectively, $\Delta \Theta$ the differential molar optical activity for the complex, $K$ is the binding constant to be determined. 


\section{Microbiological assays}

Microbiological assays were performed using E. coli K12 DH10B (Invitrogen) and $K$. rhizophila ATCC 9341 as Gram-negative and Gram-positive tester strains, respectively. ${ }^{19-22}$ The amp resistant strain was obtained by transformation of chemically-competent E. coli $\mathrm{K} 12 \mathrm{DH} 10 \mathrm{~B}$ cells by using the high-copy number plasmid pUC19 (Invitrogen), which carries the bla gene encoding a $\beta$ lactamase, according to supplier instructions.

Agar diffusion tests were performed using $5 \mathrm{~mL}$ of soft-agar i.e. $7.5 \%(\mathrm{w} / \mathrm{v})$ bactoagar (Difco) in Luria Bertani (LB) broth (Invitrogen) - containing $10^{8}$ to $10^{9}$ bacteria cells (colony forming units or $\mathrm{CFU}$ ) of tester strain. A range of concentrations (corresponding to 1, 0.1, 0.01 and $0.001 \mu \mathrm{g}$ of total $\mathrm{Ag}$ ) of the AgNP composites were directly spotted on an overlay of bacteria on agar plate. Growth inhibition halos from at least three independent replicas were observed after overnight incubation at 37 ${ }^{\circ} \mathrm{C}$.

In order to quantitatively assess antimicrobial activity, MIC and $\mathrm{MBC}$ values were calculated. In particular, different suspensions of $1 \mathrm{~mL} \mathrm{LB}$ broth containing each tester strain at the concentration of $10^{6} \mathrm{CFU} \mathrm{mL}^{-1}$ were incubated in sterile 24well plates $\left(37^{\circ} \mathrm{C}, 200\right.$ r.p.m. in orbital shaker) with different amounts of total $\mathrm{Ag}\left(0.1,0.5,1,5,10,20,50\right.$ and $\left.100 \mu \mathrm{g} \mathrm{mL}{ }^{-1}\right)$. Untreated bacterial cultivations were used as reference control condition. Each cultivation was performed in parallel triplicates. After $24 \mathrm{~h}$ of incubation, the MIC and MBC values were evaluated. The MIC was determined spectrophoto-metrically as the lowest concentration which inhibited the $90 \%$ of bacterial growth $\left(\mathrm{MIC}_{90}\right)$ in the respect of untreated cultivation in terms of OD measured at $600 \mathrm{~nm}$. The MBC, defined as the lowest concentration which causes a $99.9 \%$ decrease of the starting CFU, was determined by plating and incubating $100 \mu \mathrm{L}$ from serial dilutions of cultures on LB-agar plates overnight at $37{ }^{\circ} \mathrm{C}$ for CFU counting. Statistical test (one way ANOVA) was performed to asses significance $(p<0.05 \text { or } p<0.01)^{2 a, 22 d, 37}$ of spectrophotometric measurements (OD values) and viable cell count (CFU values) by using XLSTAT software (Addinsoft). Each measurement was obtained by three biological and technical replicates.

\section{Conclusions and final remarks}

An easy and viable photochemical protocol has been used to prepare Ag-NP nanocomposites stabilized by a polyaminocyclodextrin derivative, which have very promising antibacterial activities. More in detail, an ammoniacal Ag acetate solution in the presence of the amCD capping agent rapidly undergoes photoreduction on irradiation with a common halogen lamp; at the same time the polyamine pendant groups of the amCD function as sacrificial reducing agents, undergoing partial oxidative degradation. The composite obtained can be easily precipitated by centrifugation, and re-suspended by sonication. The characterization of the composites evidences the actual presence and partial degradation of the amCD in the system, as well as a relatively low polydispersity of the Ag metal cores, which have a significant degree of crystallinity, and tend to increase in dimension after the precipitation/re-suspension procedure. The composites obtained show remarkable antibacterial activities (measured in terms of $\mathrm{MIC}_{90}$ and $\mathrm{MBC}$ values) towards $E$. coli and $K$. rhizophila. Moreover, they positively show the ability to bind, vehicle and act synergistically with the $\beta$-lactam antibiotic ampicillin. In fact, data indicate that the Ag-NP composites enhance their antimicrobial activity in combination with sub-lethal amounts of amp. Thus, our composites appear as bioactive supramolecular systems having all the requirements to be considered as powerful and tunable antimicrobial agents.

Finally, there are a few additional points which deserve to be outlined. It is important in our opinion to stress that the photoreduction methodology adopted here provides with a very simple, inexpensive and environmental-friendly way to obtain Ag-NPs, even in large amounts. The possibility to isolate and resuspend the composite with overall negligible outcome on the characteristics and efficiency of the composite has an undoubted appeal in view of future applications. It is important to stress, in our opinion, that the observed antimicrobial activity is the outcome of the overall features of the composite, i.e. the peculiar combination of nanosized metal core, unreduced $\mathrm{Ag}^{+}$and amCD coating, all contributing to the release of $\mathrm{Ag}^{+}$ions under aerobic condition. The elucidation of the different contributions and the relevant interdependency in exerting the antibacterial activity could be an interesting point to be comparatively addressed in further dedicated studies. Moreover, the assessment of a supramolecular interaction by means of the polarimetric method is quite interesting from a methodological viewpoint, because it extends the possibility to reliably exploit this simple technique even to chiral guests. Last, due to these encouraging results, in next studies the effects of increased amounts of amp and/or different members of various antibiotic classes to be combined with PCR Ag-amCD nanocomposite will be comparatively tested, with the aim of elucidating of the intrinsic antibacterial mechanism of the silver-amCD nanocomposites, as well as of developing antimicrobial systems effective against amp resistant and multi drug resistant bacterial strains.

\section{Acknowledgements}

TEM micrographs were acquired at the Centro Grandi Apparecchiature - UniNetLab - Università di Palermo funded by P.O.R. Sicilia 2000-2006, Misura 3.15 Quota Regionale; Prof. E. Caponetti, Dr G. Nasillo and Prof. A. M. Puglia are gratefully acknowledged for useful discussion and collaboration.

\section{Notes and references}

1 K. Mijnendonckx, N. Leys, J. Mahillon, S. Silver and R. Van Houdt, BioMetals, 2013, 26, 609, and references therein.

2 (a) J. S. Kim, E. Kuk, K. N. Yu, J. Kim, S. J. Park, H. J. Lee, S. K. Kim, Y. K. Park, Y. H. Park, C. Hwang, Y. Kim, Y. Lee, D. H. Jeong and M. Cho, Nanomedicine, 2007, 3, 95; (b) M. K. Rai, S. D. Deshmukh, A. P. Ingle and A. K. Gade, J. Appl. Microbiol., 2012, 5, 841; (c) S. Agnihotri, S. Mukerji 
and S. Mukerji, Nanoscale, 2013, 5, 7328; (d) M. Rai, K. Kon, A. Ingle, N. Duran, S. Galdiero and M. Galdiero, Appl. Microbiol. Biotechnol., 2014, 98, 1951; (e) M. Rai, S. Birla, A. P. Ingle, I. Gupta, A. Gade, K. Abd-Elsalam, P. D. Marcato and N. Duran, Nanotechnol. Rev., 2014, 3, 281; $(f)$ G. Franci, A. Falanga, S. Galdiero, L. Palomba, M. Rai, G. Morelli and M. Galdiero, Molecules, 2015, 20, 8856. 3 Z. Xiu, Q. Zhang, H. L. Puppala, V. L. Colvin and P. J. J. Alvarez, Nano Lett., 2012, 12, 4271.

4 (a) A. D. Russell, Prog. Med. Chem., 1994, 31, 351; (b) O. Gordon, T. V. Slenter, P. S. Brunetto, A. E. Villaruz, D. E. Sturdevant, M. Otto, R. Landmann and K. M. Fromm, Antimicrob. Agents Chemother., 2010, 54, 4208; (c) W. J. Schreurs and H. Rosemberg, J. Bacteriol., 1982, 152, 7. 5 (a) S. Y. Liau, D. C. Read, W. J. Pugh, J. R. Furr and A. D. Russell, Lett. Appl. Microbiol., 1997, 25, 279; (b) M. Tajkarimi, D. Iyer, M. Tarrannum, Q. Cunningham, I. Sharpe, S. H. Harrison and J. L. Graves, JSM Nanotechnology \& Nanomedicine, 2014, 2, 1025.

6 (a) H. J. Park, J. Y. Kim, J. Kim, J. H. Lee, J. S. Hahn and M. B. Gu, Water Res., 2009, 43, 1027; (b) Y. Matsumura, K. Yoshikata, S. Kunisaki and T. Tsuchido, Appl. Environ. Microbiol., 2003, 69, 4278; (c) A. K. Sahoo, M. P. Sk, S. S. Ghosh and A. Chattopadhyay, Nanoscale, 2011, 3, 4226.

7 (a) A. Fernández-Lodeiro, J. Fernández-Lodeiro, C. Núñez, R. Bastida, J. L. Capelo and C. Lodeiro, Chemistryopen, 2013, 2, 200; (b) S. Saha, B. Gupta, K. Gupta and M. G. Chaudhuri, NanoTrends, 2015, 17, 31; (c) R. K. Gupta, M. P. Srinivasana and R. Dharmarajanb, Colloids Surf., A, 2011, 390, 149; (d) M. K. Corbierre and R. B. Lennox, Chem. Mater., 2005, 17, 5691; (e) S. Roux, B. Garcia, J. Bridot, M. Murielle Salomé, M. Marquette, L. Lemelle, P. Phillipe Gillet, L. Blum, P. Perriat and O. Tillement, Langmuir, 2005, 21, 2526; (f) A. M. Alkilany, S. R. Abulateefeh, K. K. Mills, A. I. B. Yaseen, M. A. Hamaly, H. S. Alkhatib, K. M. Aiedeh and J. W. Stone, Langmuir, 2014, 30, 13799.

8 (a) T. Abbasi, J. Anuradha, S. U. Ganaie and S. A. Abbasi, J. Nano Res., 2015, 31, 138; (b) A. Gangula, R. Podila, M. Ramakrishna, L. Karanam, C. Janardhana and A. M. Rao, Langmuir, 2011, 27, 15268; (c) J.-G. BocarandoChacon, M. Cortez-Valadez, D. Vargas-Vazquez, F. Rodríguez-Malgarejo, M. Flores-Acosta, P. G. ManiGonzalez, E. Leon-Sarabia, A. Navarro-Badilla and R. Ramírez-Bon, Physica E: Low-dimensional Systems and Nanostructures, 2014, 59, 15; (d) V. Dhand, L. Soumya, S. Baradwaj, S. Chakra, D. Bhatt and B. Sreedhar, Mater. Sci. Eng., C, 2016, 58, 36; (e) A. A. Kajani, A.-K. Bordbar, S. H. Zarkesh Esfahani, A. R. Khosropour and A. Razmjou, RSC Adv., 2014, 4, 61394.

9 (a) M. Zhao, L. Sun and R. M. Crooks, J. Am. Chem. Soc., 1998, 120, 4877; (b) D. Tabuani, O. Monticelli, A. Chincarini, C. Bianchini, F. Vizza, S. Moneti and S. Russo, Macromolecules, 2003, 36, 4294; (c) C. Bao, M. Jin, R. Lu, T. Zhang and Y. Zhao, Mater. Chem. Phys., 2003, 82, 812; (d) C. Bao, M. Jin, R. Lu, T. Zhang and Y. Y. Zhao, Mater. Chem. Phys., 2003, 81, 160; (e) J. Zheng, M. S. Stevenson, R. S. Hikida and P. G. Van Patten, J. Phys. Chem. B, 2002,
106, 1252; (f) H. Ye, R. W. J. Scott and R. M. Crooks, Langmuir, 2004, 20, 2915; (g) R. M. Crooks, M. Zhao, L. Sun, V. Chechik and L. K. Yeung, Acc. Chem. Res., 2001, 34, 181; (h) L. Balogh and D. A. Tomalia, J. Am. Chem. Soc., 1998, 120, 7355; (i) L. Balogh, D. R. Swanson, D. A. Tomalia, G. L. Hagnauer and A. T. McManus, Nano Lett., 2001, 1, 18; (j) K. Esumi, A. Susuki, N. Aihara, K. Usui and K. Torigoe, Langmuir, 1998, 14, 3157; (k) K. Esumi, R. Isono and T. Yoshimura, Langmuir, 2004, 20, 237; $(l)$ A. Castonguay and A. K. Kakkar, Adv. Colloid Interface Sci., 2010, 160, 76.

10 J. Szejtli, Chem. Rev., 1998, 98, 1743.

11 (a) A. Rauf Khan, P. Forgo, J. Stine and V. T. D'Souza, Chem. Rev., 1998, 98, 1977; (b) P.-A. Faugeras, B. Boëns, P.-H. Elchinger, F. Brouillette, D. Montplaisir, R. Zerrouki and R. Lucas, Eur. J. Org. Chem., 2012, 4087.

12 (a) M. V. Rekharsky and Y. Inoue, Chem. Rev., 1998, 98, 1875; (b) I. Tabushi, Y. Kiyosuke, T. Sugimoto and K. Yamamura, J. Am. Chem. Soc., 1978, 100, 916; (c) L. Liu and Q.-X. Guo, J. Inclusion Phenom. Macrocyclic Chem., 2002, 42, 1; (d) M. V. Rekharsky and Y. Inoue, J. Am. Chem. Soc., 2000, 122, 4418; (e) M. V. Rekharsky and Y. Inoue, J. Am. Chem. Soc., 2002, 124, 813; (f) K. Kano and H. Hasegawa, J. Am. Chem. Soc., 2001, 123, 10616; ( $g$ ) M. V. Rekharsky, M. P. Mayhew, R. N. Goldberg, P. D. Ross, Y. Yamashoji and Y. Inoue, J. Phys. Chem. B, 1997, 101, 87; (h) P. Lo Meo, F. D'Anna, S. Riela, M. Gruttadauria and R. Noto, Org. Biomol. Chem., 2003, 1, 1584; (i) P. Lo Meo, F. D'Anna, M. Gruttadauria, S. Riela and R. Noto, Tetrahedron, 2004, 60, 9099.

13 (a) R. Breslow and S. D. Dong, Chem. Rev., 1998, 98, 1997; (b) J. Bjerre, C. Rousseau, L. Marinescu and M. Bols, Appl. Microbiol. Biotechnol., 2008, 81, 1; (c) W. Zhao and Q. Zhong,J. Inclusion Phenom. Macrocyclic Chem., 2012, 72, 1. 14 (a) K. Ukeama, F. Hirayama and T. Irie, Chem. Rev., 1998, 98, 2045; (b) T. Loftsson and M. E. Brewster, J. Pharm. Pharmacol., 2011, 63, 1119; (c) V. Bonnet, C. Gervaise, F. Djedaïni-Pilard, A. Furlan and C. Sarazin, Drug Discovery Today, 2015, 20, 1120; (d) Q.-D. Hu, G.-P. Tang and P. K. Chu, Acc. Chem. Res., 2014, 47, 2017.

15 (a) S. Pande, S. K. Ghosh, S. Praharaj, S. Painigrahi, S. Basu, S. Jana, A. Pal, T. Tsukuda and T. Pal, J. Phys. Chem. C, 2007, 111, 10806; (b) Y. Huang, D. Li and J. Li, Chem. Phys. Lett., 2004, 389, 14; (c) P. R. Gopalan, Int. J. Nanosci., 2010, 9, 487; (d) B. D. Loganathan and A. B. Mandal, RSC Adv., 2013, 3, 5238; (e) J. Liu, S. Mendoza, E. Román, M. J. Lynn, R. Xu and A. E. Kaifer, J. Am. Chem. Soc., 1999, 121, 4304; (f) J. Liu, W. Ong, E. Román, M. J. Lynn and A. E. Kaifer, Langmuir, 2000, 16, 3000; (g) J. Liu, W. Ong, A. E. Kaifer and C. Peinador, Langmuir, 2002, 18, 5981; (h) Y. Guo, Y. Zhao, H. Wu, M. Fan, Y. Wei, S. Shuang and C. Dong, J. Inclusion Phenom. Macrocyclic Chem., 2014, 78, 275; (i) X. Li, Z. Qi, K. Liang, X. Bai, J. Xu, J. Liu and J. Shen, Catal. Lett., 2008, 124, 413.

16 P. Lo Meo, F. D'Anna, M. Gruttadauria, S. Riela and R. Noto, Carbohydr. Res., 2012, 347, 32.

17 M. Russo, F. Armetta, S. Riela, D. Chillura Martino, P. Lo Meo and R. Noto, J. Mol. Catal. A: Chem., 2015, 408, 250. 
18 (a) S. Srinivasachari, K. M. Fichter and T. M. Reineke, J. Am. Chem. Soc., 2008, 130, 4618; (b) A. Méndez-Ardoi, M. GómezGarcía, C. Ortiz Mellet, N. Sevillano, M. D. Girón, R. Salto, F. Santoyo-Gonzáles and J. M. García Fernández, Org. Biomol. Chem., 2009, 7, 2681; (c) J. Deng, N. Li, K. Mai, C. Yang, L. Yan and L.-M. Zhang, J. Mater. Chem., 2011, 21, 5273; (d) F. Ortega-Caballero, C. Ortiz Mellet, L. Le Gourriérec, N. Guilloteau, C. Di Giorgio, P. Vierling, J. Defaye and J. M. García Fernández, Org. Lett., 2008, 10, 5143-5146; (e) C. Ortiz Mellet, J. M. Benito and J. M. García Fernández, Chem.-Eur. J., 2010, 16, 6728; (f) C. Byrne, F. Sallas, D. K. Rai, J. Ogier and R. Darcy, Org. Biomol. Chem., 2009, 7, 3763.

19 A. N. Brown, K. Smith, T. A. Samuels, J. Lu, S. O. Obare and M. E. Scott, Appl. Environ. Microbiol., 2012, 78, 2768.

20 F. Okafor, A. Janen, T. Kukhtareva, V. Edwards and M. Curley, Int. J. Environ. Res. Public Health, 2013, 10, 5221.

21 S. Ruden, K. Hilpert, M. Berditsch, P. Wadhwani and A. S. Ulrich, Antimicrob. Agents Chemother., 2009, 53, 3538.

22 (a) S. Roberto, L. Botta, G. Gallo and A. M. Puglia, Macromol. Mater. Eng., 2015, 300, 1268; (b) L. Liu, J. Yang, J. Xie, Z. Luo, J. Jiang, Y. Y. Yang and S. Liu, Nanoscale, 2013, 5, 3834; (c) S.-K. Li, Y.-X. Yan, J.-L. Wang and S.-H. Yu, Nanoscale, 2013, 5, 12616; (d) F. Baldi, S. Daniele, M. Gallo, S. Paganelli, D. Battistel, O. Piccolo, C. Faleri, A. M. Puglia and G. Gallo, BioMetals, 2016, 29, 321.

23 B. I. Gorin, R. J. Riopelle and G. R. J. Thatcher, Tetrahedron Lett., 1996, 37, 4647.

24 (a) F. Kim, J. H. Song and P. Yang, J. Am. Chem. Soc., 2002, 124, 14316; (b) Y. Lei, G. Gao, W. Liu, T. Liu and Y. Yin, Appl. Surf. Sci., 2014, 317, 49; (c) P. E. Cardoso-Avila, J. L. Pichardo-Molina, C. Murali Krishna and R. CastroBeltran, J. Nanopart. Res., 2015, 17, 160; (d) H.-H. Park, X. Zhang, K. W. Lee, A. Sohn, D.-W. Kim, J. Kim, J.-W. Song, Y. S. Choi, H. K. Lee, S. H. Yung, I.-G. Lee, Y. D. Cho, H.-B. Shin, H. K. Sung, K. H. Park, H. K. Kang, W.-K. Park and H.-H. Park, Nanoscale, 2015, 7, 20717.

25 J. Hu, J. Wang, T. H. Nguyen and N. Zheng, Beilstein J. Org. Chem., 2013, 9, 1977.

26 (a) B. Tang, L. Sun, J. Li, M. Zhang and X. Wang, Chem. Eng. J., 2015, 260, 99; (b) R. Jin, Y. Charles Cao, E. Hao, G. S. Metraux, G. C. Schatz and C. A. Mirkin, Nature, 2013,
425, 487; (c) B. Kim and J. Lee, Mater. Chem. Phys., 2015, 149, 678.

27 I. Sondi and B. Salopek-Sondi, J. Colloid Interface Sci., 2004, 275, 177.

28 (a) J. P. Ruparelia, A. K. Chatteriee, S. P. Duttagupta and S. Mukherji, Acta Biomater., 2008, 4, 707; (b) D. Paredes, C. Ortiz and R. Torres, Int. J. Nanomed., 2014, 9, 1717; (c) S. Jaiswal, B. Duffy, A. K. Jaiswal, N. Stobie and P. McHale, Int. J. Antimicrob. Agents, 2010, 36, 280.

29 P. F. Andrade, A. F. de Faria, D. S. da Silva, J. A. Bonacin and M. d. C. Gonçalves, Colloids Surf., B, 2014, 118, 289. Comparable results had been obtained also by Jaiswal et al., see ref. $28 c$..

30 (a) C. Marambio-Jones and E. M. V. Hoek, J. Nanopart. Res., 2010, 12, 1531; (b) J. R. Morones, J. L. Elechiguerra, A. Camacho, K. Holt, J. B. Kouri, J. Tapia Ramírez and M. J. Yacaman, Nanotechnology, 2005, 16, 2346; (c) W.-R. Li, X.-B. Xie, Q.-S. Shi, H.-Y. Zeng, Y.-S. Ou-Yang and Y.-B. Chen, Appl. Microbiol. Biotechnol., 2010, 8, 1115; (d) V. K. Sharma, R. A. Yngard and Y. Lin, Adv. Colloid Interface Sci., 2009, 145, 83.

31 M. Smekalova, V. Aragon, A. Panacek, R. Prucek, R. Zboril and L. Kvitek, Vet. J., 2015, 209, 174.

32 I. S. Hwang, J. H. Hwang, H. Choi, K. J. Kim and D. G. Lee, J. Med. Microbiol., 2012, 61, 1719.

33 A. M. Fayaz, K. Balaji, M. Girilal, R. Yadav, P. T. Kalaichelvan and R. Venketesan, Nanomedicine: Nanotechnology, Biology and Medicine, 2010, 6, 103.

34 (a) P. Lo Meo, F. D'Anna, S. Riela, M. Gruttadauria and R. Noto, Tetrahedron Lett., 2006, 47, 9099; (b) P. Lo Meo, F. D'Anna, S. Riela, M. Gruttadauria and R. Noto, Tetrahedron, 2007, 63, 9163; (c) P. Lo Meo, F. D'Anna, S. Riela, M. Gruttadauria and R. Noto, Tetrahedron, 2009, 65, 2037.

35 D. A. Mosselhy, M. A. El-Aziz, M. Hanna, M. A. Ahmed, M. M. Husien and Q. Feng, J. Nanopart. Res., 2015, 17, 473.

36 A. Roupas and J. S. Pitton, Antimicrob. Agents Chemother., 1974, 5, 186.

37 G. Gahlawat, S. Shikha, B. S. Chaddhu, S. R. Chaudhuri, S. Mayilraj and A. R. Choudhouri, Microb. Cell Fact., 2016, 15, 25. 